\title{
Study on the Morphology of Genus Arabidopsis in Iran
}

\author{
Mahlagha Aghajafari ${ }^{1}$, Behrooz Shahsavan Behboodi ${ }^{2}$, Saeedeh Pirayesh ${ }^{3}$ \\ ${ }^{1}$ Botany Department, Payame Noor University, Tehran, Iran; ${ }^{2}$ University College of Science, Faculty of Biology, University of Te- \\ hran, Tehran, Iran; ${ }^{3}$ Plant Pathology, Science and Research Branch, Islamic Azad University, Tehran, Iran. \\ Email: behboodi@khayam.ut.ac.ir
}

Received August 12 ${ }^{\text {th }}, 2013$; revised October $13^{\text {th }}, 2013$; accepted October $25^{\text {th }}, 2013$

Copyright (C) 2013 Mahlagha Aghajafari et al. This is an open access article distributed under the Creative Commons Attribution License, which permits unrestricted use, distribution, and reproduction in any medium, provided the original work is properly cited.

\begin{abstract}
In the present research, we have investigated morphologicaltraits of different organs of Arabidopsis species in Iran. Trichomes on the aerial parts of three species were studied under anatomical microscopy. The species exist in Iran include: Arabidopsis thaliana (Heynh), Arabidopsis pumila (steph) and Arabidopsis wallichii (Hook \& thomas). The form of trichomes, basal and stemleaves, fruit length, the attitude of fruit, the existence of trichomes on the fruit, and the color ofpetal are morphological traits which separate the species. Anatomical traits of the leaf and stem of studied species were analyzed using an optical microscope. In the stem, some traits such as the shape of stem in transverse incision, the thickness of skin, the existence of supporting tissue around phloem, the number of xylem and phloem and the wavy form of stele were distinct in the three species. In the leaf, some traits such as the shape of leaf, the number of palisade parenchyma layers, the uniformity of mesophyll tissue, and the density of trichomes were different in the three species. No significant difference has been observed in the study of reproductive meristem, except in A. wallichii. The only difference was related to the size of reproductive meristem of two species and the number of flowers produced from the meristems.
\end{abstract}

Keywords: Morphological Traits; Anatomical Traits; A. wallichii; A. pumila; A. thaliana; Meristems

\section{Introduction}

The genus Arabidopsis belongs to Cruciferae family. The members of this family are distributed in all continents of the world. However, north temperate regions, mediterranean and the Iran-Turan regions show the most population [1]. As currently delimited, the Brassicaceae comprise 49 tribes, 321 genera, and 3660 species. Of these, 20 genera and 34 species remain to be assigned to tribes. These figures differ substantially from those estimated five years ago, in which 25 tribes, 338 genera, and 3709 species were recognized. Of those 338 genera, 37 are treated herein as synonyms, and 21 genera (10 reestablished and 11 new) have since been added [2].

The species previously introduced in Iran was: $A$. wallichii, A. pumila and A. Thaliana [3]. There are no supportive data regarding its geographic origin. A. thaliana evolved in SW Asia [4]. A. thaliana species is mostly distributed in northern cities of Iran. A. wallichii is north east of Iran and A. pumila is observed in most provinces of Iran [5]. The name of Arabidopsis was first recom- manded by Decandoll as a section of genus Sisymbrium Linneaus [6]. Since the first half of the twentieth century, when Redei introduced $A$. thaliana as a proper herbal model in scientific researches, taxonomistes decided to remove Arabidopsis from the rank of section and promoted it to the rank of genus [7]. The characteristics such as the smallness of plant, short life cycle, abondant production, self-fertilization, low chromosome number, small genome size, and etc, make A. thalianasuitable for experimental tests [4]. The genus Arabidopsis was first introduced by $A$. thaliana species. Indiscriminate expansion of the genus, merely due to the similarities in linear fruits and branched trichomes, brings the number of species of genus to 59 species [8]. Unscientific development of the genus provoked the researchers to start extensive studies on the field of molecular, genetic and phylogenetic. Research results led to the removal of 50 species from this genus [9]. At present, Arabidopsis genus includes 9 species and 8 subspecies. 9 species are all native to Europe and 2 species are seen in the north and northeast Asia. Nitrogen and sulphur-rich compounds such as 
glucosinolates and indole alkaloid are observed in Cruciferae family. These materials have a defensive role against microorganisms and herbivore insects. Researches revealed that indole alkaloids such as camalexin, indole glucosinolates oxin are synthesized in this genus. Researchers believe that the ability to synthe size and accumulate cytotoxic alkaloids depends on more than one active enzyme complex [10]. The goal of this research is collecting more information regarding those morphological and morphogenesis traits that result in segregation and the separation of species and are important in taxonomy science.

\section{Material and Methods}

A. Thaliana and A. Pumila were collected in the anthesisstage from the natural habitat (Table 1). Followed by confirming their identification in Evin herbarium, some of them were maintained as herbaria. Some fragments of stem, leaf and reproductive meristimwere fixd in FAA and glutaraldehyde $5 \%$ solution and some fragments of stem and leaf of each three species were maintained in $8 \%$ ferman solution. Samples stored in $8 \%$ ferman were cut with razor blade andthe samples were stained by greenmethyl and red carmen. Samples stored in FAA and $5 \%$ glutaraldehyde were molded after washing with water, dehydratation by increasing degree of alcohol, clearing with toluene and paraffin infiltration into the tissue [11]. The molds were cut into 10 micrometer sections using a Leica 2045 microtome. The sections were glued onto lamella by using albumin glue. After deparaf finization, were stained byallendorfer, hematoxylin, methyl green pyronine, and periodic acid schiff (pas) solutions. Samples were dehydrated and then became permanent on the lamella by antlanglue. In order to observe the trichomes and to compare them, SZ51 Anatomical microscope was applied.

At the end, all samples were carefully observed by means of optical microscope and photos were taken by Canoncamera, SD1000.

The collected samples in the nature were powdered under dry shadow and by mill, except $A$. wallichii. About 20 gram powder was obtained from each species. The powders were extracted by methanol separately for 24 hours. The filtered extract was partially purified by vacuumdistillation (Bushi 461 model). 5 grams of each extract was mixed with $2 \mathrm{~N} \mathrm{HCl}$ and $\mathrm{NaCl}$ and then infilterated. The obtained extracts were examined into experimental tubes by Myers' reagent. To confirm the existence of alkaloid, Ammoniac was added to each acidic extracts till the $\mathrm{pH}$ reaches to 9 . Then $10 \mathrm{cc}$ chloroform was added to each basic solution and the mixture was poured into a separating funnel. After gently shaking the mixture, the chloroform phase was separated from the mixture. Chloroform adding was repeated three times
Table 1. Collective list and placement of various study types in anatomical survey.

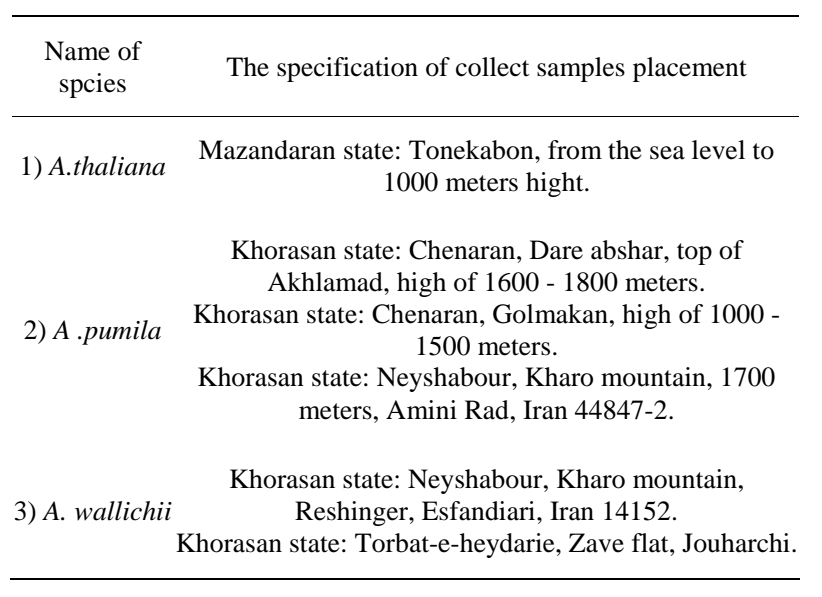

and chloroform solutions were collected in a container. After distillation of the solutions and adding $2 \mathrm{~N} \mathrm{HCl}$, sample was examined by Myers' reagent

\section{Results}

Three species studied were similar in many morphologicand anatomic traits (Figures 1, 2). The mostimportant morphological traits which cause the species be differentiated from each other is shown in Table 2. The most important morphological traits from the stem cross-sections of studied species are as follows (Figures 3, 4).

In A. thaliana: relatively round stem in the cross section, monolayer and stomatous epidermis,vascular bundle with almost 9 - 11 bundles, wavy stele, and simple, 2 or 3 branched trichomes.

In A. pumila: polyhedral and angular stem in the cross section, monolayer and stomatous epidermis, vascular bundle with 11 - 15 bundles, wavy formstele, 2 - 4 branched trichomes, and outgrowth the base

In A. wallichii: relatively round stem in the cross section, monolayer and stomatous epidermis,very thick cuticle, vascular bundle with 11 - 13 bundles, stele with a little wave, tall dendroid trichomes, and the existence of a supporting tissue on top of the phloem (Figure 5).

The most important anatomical traits of leaf in studied species are as follows (Figure 6).

In A. thaliana: A monolayerupper and lower epidermis, variable mesophylltissue, palisade parenchymaon the top, sponge parenchyma under the leaf, variable mesophyllinthe main vein, alittle outgrowth of distal surface of leaf at the main vein.

In A. pumila: A monolayer upper and lower epidermis, variable mesophyll tissue, uniform mesophyll on the main vein, a relatively much outgrowth of distal surface of leaf on the main vein.

In A. wallichii: A monolayer upper and lower epidermis, more than one layer in the palisade tissue of paren- 
Table 2. Compared of same various type of morphology traits in case study.

\begin{tabular}{|c|c|c|c|c|c|}
\hline \multicolumn{3}{|c|}{ Morphology traits of organs } & A. thaliana & A. pumila & A. wallichii \\
\hline Stem & \multicolumn{2}{|c|}{ Trichom } & $\begin{array}{l}\text { Bottom of stem has trichom } \\
\text { Top of stem is trichomeless }\end{array}$ & $\begin{array}{l}\text { From the bottom to the top } \\
\text { of stem has trichom }\end{array}$ & \\
\hline \multirow{3}{*}{ Leaf } & \multirow{2}{*}{ Basic leaves } & Form & complete & Toothed & Pectinate \\
\hline & & & Low & Many & A lot \\
\hline & $\begin{array}{l}\text { Stem } \\
\text { Leave }\end{array}$ & Petiole & Short petiole & Epetiolate & Epetiolate \\
\hline \multirow{3}{*}{ Fruit } & \multicolumn{2}{|c|}{ Length } & $5-17 \mathrm{~mm}$ & $15-60 \mathrm{~mm}$ & $40-70 \mathrm{~mm}$ \\
\hline & \multicolumn{2}{|c|}{ Shape } & ascending & Rararearcuatus & Arcuatus \\
\hline & \multicolumn{2}{|c|}{ Trichome } & epetiolate & Full of petiole & Puberulus \\
\hline Flower & \multicolumn{2}{|c|}{ Color of petal } & white & Yellow & Violet \\
\hline
\end{tabular}

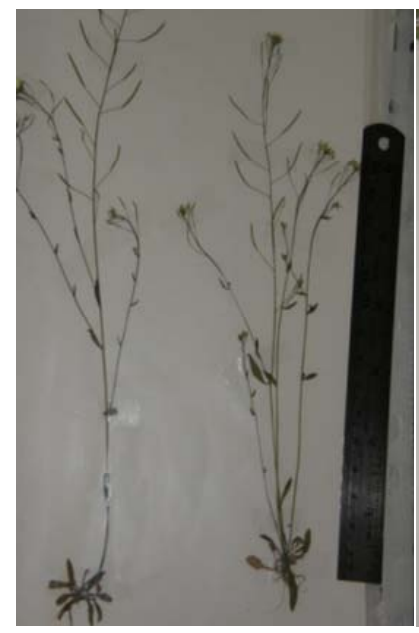

A. thaliana

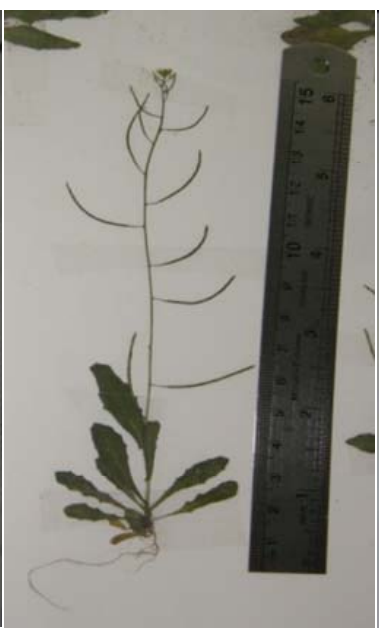

A. pumila

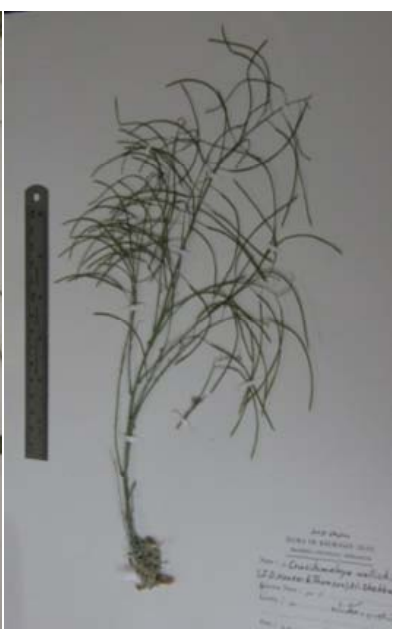

A. wallichii

Figure 1. Samples of herbarium.

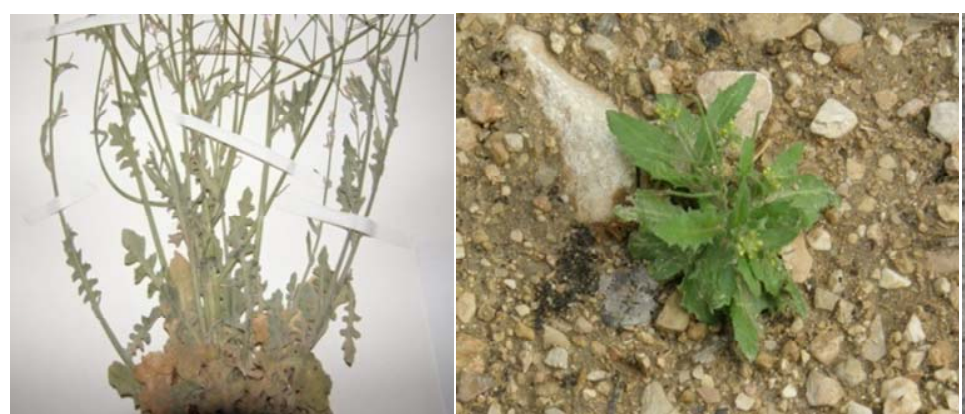

A. thaliana
A. pumila

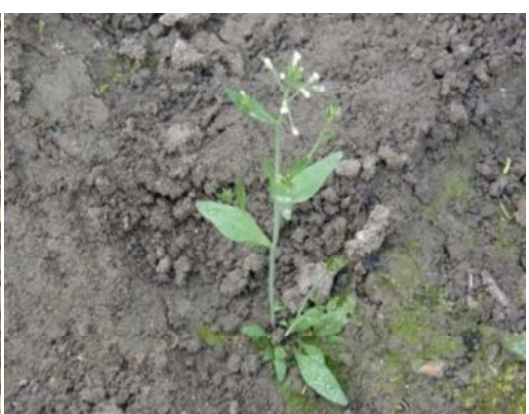

A. wallichii

Figure 2. The species collected in Iran.

chyma, uniform mesophyll tissue at the main vein, a relatively small protrusionon the dorsal surface of leaf at the midvein.

The results of the histological structure and the reproductive meristem of species:
A. thaliana and A. pumila: In terms of meristem structure, there was no significant difference between the two reproductive meristems of these two species. We can see the feloral meristem of $A$. thalianain Figure 7.

The size of meristem and the number of produced 


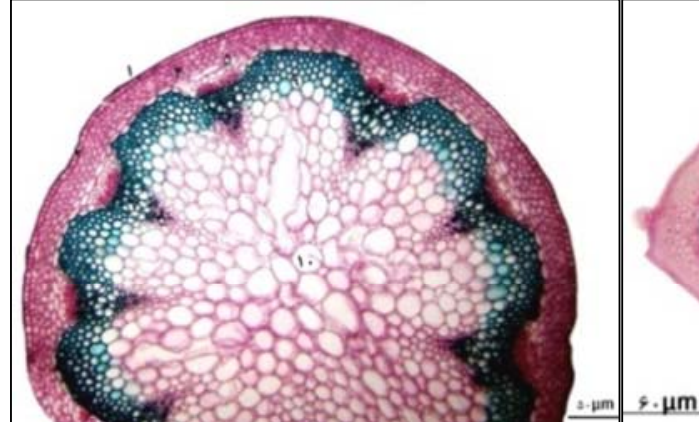

A. thaliana

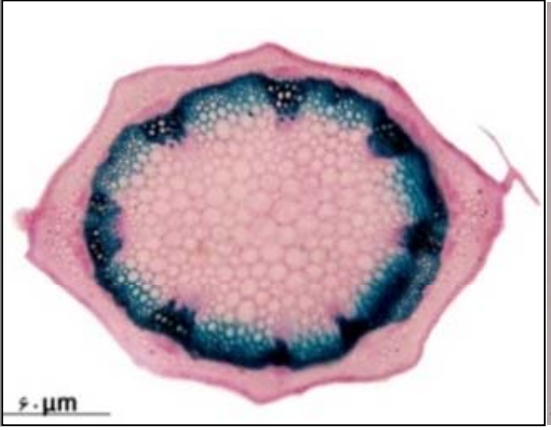

A. pumila

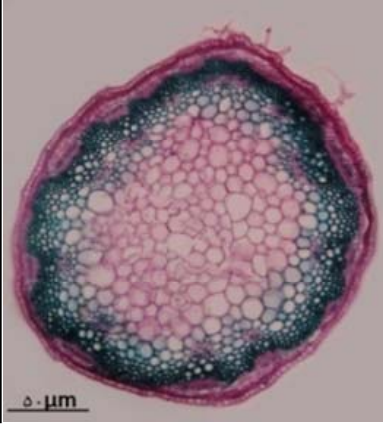

A. thaliana

Figure 3. The cross section of stem in three study species.

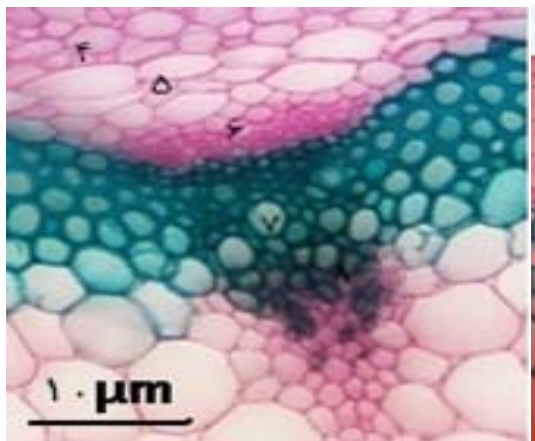

A. thaliana

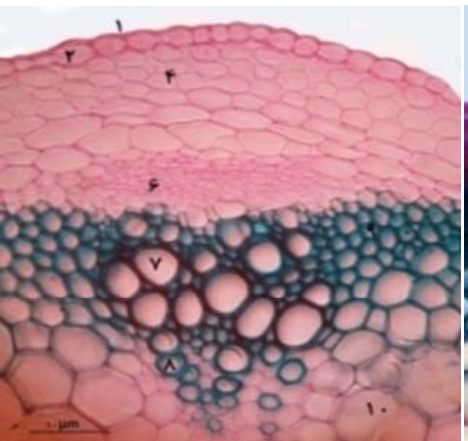

A. pumila

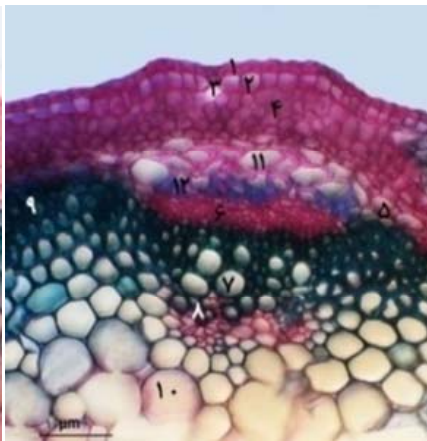

A. thaliana

Figure 4. Part of stem in three study species: 1—cuticule; 2-epiderme; 3-stomata; 4—cortexparanchyma; 5—endoderm; 6-phloem tissue; 7-metaxylem; 8-protoxylem; 9-fiber; 10-collenchyma; 11—sclerenchyma.

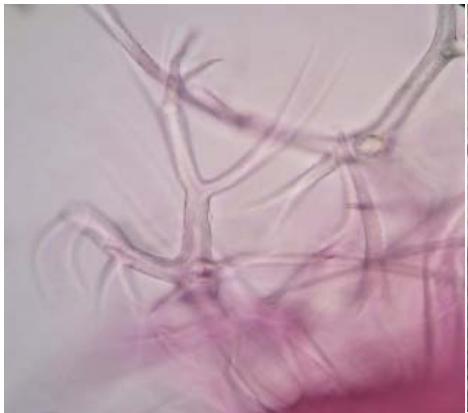

A. thaliana

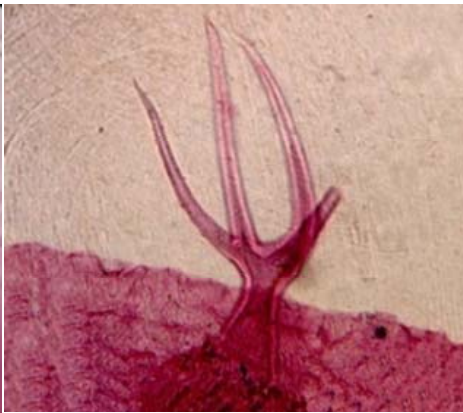

A. pumila

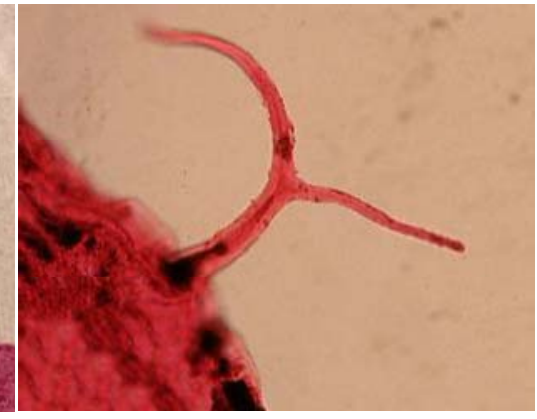

A. thaliana

Figure 5. The trichome in three study species.

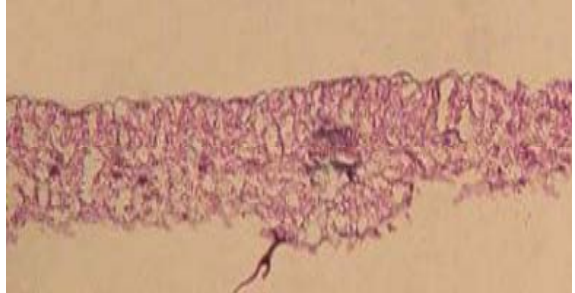

A. thaliana

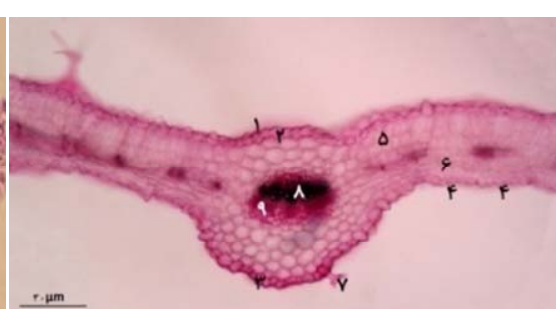

A. pumila

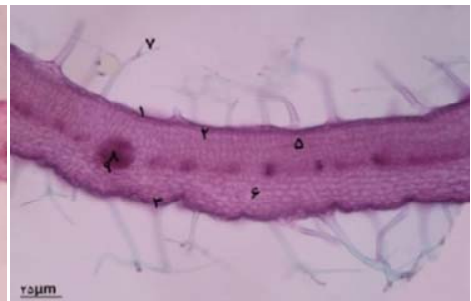

A. thaliana

Figure 6. The cross section of leaf in three study species: 1-cuticle; 2 -adaxial epiderme; 3-abaxialepiderme; 4-stomata; 5-palisadparenchyma; 6-spongyparenchyma; 7-trichume; 8-xylemtissue; 9-phloem tissue.

flowers in A. pumila was more than A. thaliana.

The results of alkaloid test, in the two stages of experi- ment, were positive for $A$. thaliana and were negative for A. pumila. The experiment was repeated three times and 


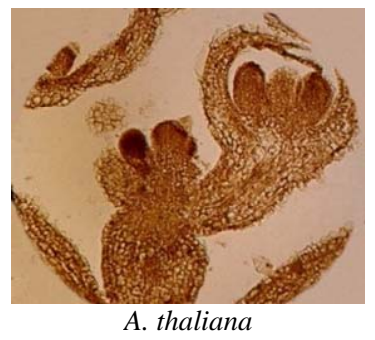

Figure 7. The radial section of floral meristem.

the results of experiment were similar in all three cases.

\section{Discussion}

With regard to the fact that $A$. thaliana is a unique species of the genus Arabidopsis and most of its morphological, anatomical, cellological, and genetic traits are known in the world. Therefore, all traits studied on $A$. pumila and $A$. wallichii were compared with $A$. thaliana. According to the extensive studies performed on the plants of genus Arabidopsis by herbal researchers, plants are included in the genus Arabidopsis which are in the context of following attributes:

Having a simple trichome, not having a lug in stem and leaf, flowers in white to light purple, trichomeless fruit, fruit with perpendicular and glabrous tail, aflat or round fruit in the section.

In addition to the above morphological traits, in the present study most other traits are shown such as:

The presence of palisade tissue in main vein, the wavy form of stele, and thepositive alkaloid test are of traits which separate $A$. thaliana from two other species. This difference in alkaloid may be related to time and stage of growth of plant. Therefore this test was not the suitable case for us to separate this spieces.

First time, A. parvula has been reported by Akhany from Mighan desert region of Arak, Iran in 1988 [12]. It is different from $A$. thaliana due to lack of petals, no trichome in the whole plant, leaves without petioles and stems with a difference of calcareous or salty environment. These species outside the genus Arabidopsis was transferred to the genus Thellungiella.

With regard to the research results of researchers such as Price (1994), AL Shehbaz (1994) and O’kane (1997), $[9,13,14]$, A pumila was removed from the genus Arabidopsis due to the morphology, anatomy and genetic differences and was moved to the genus Olimarabidopsis.

A. wallichii species was removed from the genus Arabidopsis and was moved to the genus Crucihimalyala. According to the extensive scientific researches and the present study, only one species of the genus Arabidopsis remains in Iran, which is the unique species of Arabidopsis thaliana.

Therfore previous researchs introduced three species allegedly belonging to Arabidopsis in Iran but they be- long to three different genera of three unrelated tribes. Arabidopsis thaliana belongs to the tribe Camelineae; A. wallichiiis Crucihimalaya of the tribe Crucihimalayeae, and A. pumilais Olimarabidopsis of the tribe Alyssopsideae.

\section{REFERENCES}

[1] R. C. Rollins, “A Monographic Study of Arabis in Western North America,” Rhodora, Vol. 43, No. 513, 1993, pp. 289-325.

[2] I. A. Al-Shehbaz, "A Generic and Tribal Synopsis of the Brassicaceae (Cruciferae),” Taxon, Vol. 61, No. 5, 2012, pp. 931-954.

[3] I. C. Hedge, “Arabidopsis,” In: F. Iranica and K. H. Rechinger, Eds., Arabidopsis in Flora Iranica, Akademische Druck-u. Verlagsandstalt, Graz, 57, 1968, pp. 328334.

[4] G. P. Redei, “Arabidopsis as a Genetic Tool,” Annual Review of Genetics, Vol. 9, 1975, pp. 111-127. http://dx.doi.org/10.1146/annurev.ge.09.120175.000551

[5] K. H. Rechinger, “Arabidopsis in Flora Iranica,” Flora Iranica, Vol. 57, 1965-1977, pp. 328-332.

[6] A. P. de Candolle, "Regni Vegetabilis Systema Naturale," Treuttel and Würtz, Paris, 1821, p. 68.

[7] I. A. Al-shehbaz, "The Brassicaceae Family: A Technical Overview,” Missiuro Botanical Gardern Poster, 2003.

[8] S. L. O’kane Jr. and I. A. Al-Shehbaz, “A Synopsis of Arabidopsis (Brassicaceae),” Novon, Vol. 7, No. 3, 1997, pp. 323-327. http://dx.doi.org/10.2307/3391949

[9] M. Koch, et al., "Molecular Systematic of the Brassicaceae Evidence from Coding Platidicmatk and Nuclear Chromosomes Sequence,” American Journal of Botany, Vol. 88, 3, 2001, pp. 534-544.

[10] R. Croteau, T. M. Kutchan and N. G. Lewis, "Natural Products (Secondary Metabolites),” In: Natural Products (Secondary Metabolites). Biochemistry and Molecular Biology of Plants, American Society of Plant Physiologists, Rock Ville, 2000, pp. 1250-1318.

[11] B. B. Shahsavan, "Cytochemistry Lecturenotes,” Tehran University, Tehran, 1991.

[12] H. Akhani, "Notes on the Flora of Iran: 4. Two New Records and Synopsis of the New Data on Iranian Cruciferae Since Flora Iranica,” Candollea, Vol. 58, No. 2, 2003, pp. 369-385.

[13] R. A. Price, J. D. Palmer and I. A. Al-Shehbaz, "Systematic Relationships of Arabidopsis: A Molecular and Morphological Perspective in Arabidopsis,” In: E. M. Meyerowitz and C. R. Somerville, Eds., Systematic Relationships of Arabidopsis: A Molecular and Morphological Perspective in Arabidopsis, Harbor Laboratory, Cold Spring Harbor, 1994, pp. 7-19.

[14] I. A. Al-Shehbaz, "Erysimum hedgeanum (Brassicaceae), a New Name Replacing Arabidopsis Erysimoides,” Novon, Vol. 4, No. 1, 1994, pp. 1-2.

http://dx.doi.org/10.2307/3391687 